\title{
Recent Development of Bio-Reducible Polymers for Efficient Gene Delivery System
}

\author{
Sung Wan Kim ${ }^{1,2 *}$, Joung-Pyo Nam ${ }^{1,2}$, Soyoung Kim ${ }^{1,2}$, Yong Kiel Sung ${ }^{1,2,3}$ \\ 'Department of Pharmaceutics and Pharmaceutical Chemistry, University of Utah, Salt Lake City, Utah 841 12, USA \\ ${ }^{2}$ Center for Chemically Controlled Delivery, University of Utah, Salt Lake City, Utah 84112 , USA \\ ${ }^{3}$ Department of Chemistry, Dongguk University, Phildong-ro 1 Gil, Chung-gu, Seoul 04620, Korea
}

Article Info

\section{Article Notes}

Received: July 16, 2018

Accepted: September 10, 2018

\section{${ }^{*}$ Correspondence:}

Dr. Sung Wan Kim, Department of Pharmaceutics and

Pharmaceutical Chemistry, University of Utah, Salt Lake City,

Utah 84112, USA, Center for Chemically Controlled Delivery,

University of Utah, Salt Lake City, Utah 84112, USA Telephone

No: 8018038789; E-mail: SW.Kim@pharm.utah.edu.

(c) 2018 SW. Kim. This article is distributed under the terms of the Creative Commons Attribution 4.0 International License.

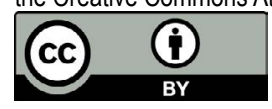

\section{Keywords:}

Gene delivery

bio-reducible polymer

PEl-conjugated polymer

DNA

RNA

cancer cell

\section{ABSTRACT}

The design of a gene delivery system requires a complete understanding of the interaction between targeting cell and delivery systems. The poly(cystaminebis- (acrylamide)-diaminohexane) (poly(CBA-DAH)) has been confirmed as a bio-reducible efficient delivery carrier among the various systems. Poly(ethylenimine) (PEI, $1.8 \mathrm{kDa}$ ) was conjugated to poly(CBA-DAH) via a disulfide bond. The PEI conjugated poly(CBA-DAH) (PCDP) was able to bind with pDNA at a very low molecular weight ratio and form the polyplexes with nano-size and positive surface charge. To confirm the transfection efficiency, the plasmid DNA encodes with the luciferase reporter gene and green fluorescent protein reporter gene have made to use a bio-reducible efficient gene delivery. The PCDP polyplexes show 10 times higher gene transfection efficiency than Lipofectamine ${ }^{\circledR}$ polyplexes in bio-mimic in vivo condition. It has been reviewed that the bio-reducible $\mathrm{PEI}(1.8 \mathrm{kDa})$ conjugated poly(CBA-DAH) is finally concluded as an efficient gene delivery carrier.

\section{Introduction}

Gene therapy has used in the administration of genetic materials such as plasmid deoxyribonucleic acid (pDNA), messenger ribonucleic acid (mRNA), and small interfering ribonucleic acid (siRNA) into specific host cells for the treatment of acquired disorders ${ }^{1-3}$. The gene delivery systems consist of three components: i) a plasmid-based gene expression system that controls the function of a gene within the targeting cell, ii) a gene that encodes a specific therapeutic protein, and iii) a gene delivery system that controls the delivery of the gene expression plasmid to specific location within the body ${ }^{4,5}$.

The gene therapy had only focused on the inherited genetic disorders in the early days, however, it has recently applied to the different disorders including various forms of cancers, emphysema, diabetes, hemophilia, vascular diseases, some autosomal dominant and neurodegenerative disorders ${ }^{6,7}$. Therefore, there are many different kinds of limitation in delivering each genetic materials. Actually, the genetic materials get the lowest cellular uptake efficiency due to their hydrophilic anionic charge density and susceptibility toward nuclease-mediated degradation ${ }^{8,9}$. In order to solve the problems, the carriers as vectors should not degrade for genetic materials. Adenovirus, adeno-associated virus, herpes simplex virus, and lentivirus as viral vectors use as vehicle agents for efficient gene transfer. However, such viral vectors consist of serious problems concerned inflammation, immunogenicity, carcinogenicity 
and inflammatory response $\mathrm{e}^{10,11}$. On the other hands, nonviral vectors give a lower efficiency of gene transfection comparing viral vectors. Non-viral vectors are less toxic and immunogenic effects than viral vectors ${ }^{12,13}$.

In our laboratory over the past decade, the various kinds of polycationic polymers for genetic materials have been synthesized and characterized to be evaluated their applications in this field ${ }^{14-16}$. The poly(ethylenimine) (PEI) conjugated poly(crystamine bis(acrylamide)diaminohexane)[poly(CBA-DAH)] has been synthesized to decrease weight ratio and increase transfection efficiency. Poly(CBA-DAH) is composed of multiple disulfides, which can be cleaved in the cytoplasm by an intracellular reducing agent such as glutathione(GSH) ${ }^{17-20}$.

The GSH is composed of triple-peptide, which is synthesized in the cytosol from precursor amino acids ${ }^{21}$. The design of PEI-conjugated bio-reducible polymer for efficient gene delivery has investigated to confirm the successful vectors and polyplexes formation with pDNA. Poly(CBA-DAH) was characterized using the luciferase reporter gene (gWiz-Luc) and the green fluorescent protein (gWiz-GFP) ${ }^{22-27}$. Vascular endothelial growth factor (VEGF) siRNA expressing plasmid (pshVEGF) as a therapeutic gene has been reviewed to investigate the therapeutic efficiency in various cancer cells.

\section{PEI-conjugated bio-reducible polymers}

\section{Synthesis and characterization of poly(CBA-DAH)- PEI (PCDP)}

In order to increase the transfection efficiency and to decrease the weight ratio when the polyplexes formed with pDNA, a novel bio-reducible polymer with poly(CBA-DAH) and PEI(1.8 kDa) has been designed. PEI can introduce high binding ability with pDNA as well as enhanced endosome escape ability of pDNA from the polyplexes, leading to decreased weight ratio and increased transfection efficiency ${ }^{28,29}$. In order to introduce the disulfide bond between poly(CBA-DAH) and PEI $1.8 \mathrm{kDa}$, Traut's reagent and SPDP were used to synthesize. The conjugation ratios of sulfhydryl groups measured by Ellman's reagent. Each reaction steps monitored by TLC. Poly(CBA-DAH)-PEI was made with different conjugation ratios of PEI such as 1,4 , and 8 , to compare the effect of the conjugation ratio. In the case of conjugation ratio of 1 , there was not a significant difference when compared to poly(CBA-DAH), and in the case of conjugation ratio of 8 , it aggregated during the final step of the synthesis. Poly(CBA-DAH)-PEI with conjugation ratio of 4 for experiments can be confirmed its potential as a gene delivery carrier. The synthesis and conjugation ratios of poly(CBA-DAH)-PEI have been confirmed by ${ }^{1} \mathrm{H}$ NMR. The poly(CBA-DAH) used as a backbone was characterized in the previous work ${ }^{16}$. The peak assignments of poly(CBADAH), PEI $1.8 \mathrm{kDa}$, PEI $1.8 \mathrm{kDa}$, and PCDP were classified in the data. The proton peaks of poly(CBA-DAH) and PEI were shifted downfield due to steric hindrance caused by the conjugation between $\mathrm{P}(\mathrm{CBA}-\mathrm{DAH})$ and $\mathrm{PEI}^{30}$. In addition, the conjugation ratio of PEI to the PCDP has been calculated by the ratio of the integration of the proton spectra peaks in poly(CBA-DAH) $\left(-\mathrm{NCH}_{2} \mathrm{CH}_{2} \mathrm{CH}_{2} \mathrm{CH}_{2}-\mathrm{CH}_{2} \mathrm{CH}_{2} \mathrm{NH}_{2}\right)$ and $\mathrm{CH}_{2}$ of PEI. The ${ }^{1} \mathrm{H}-\mathrm{NMR}$ results show that the PCDP have successfully synthesized in the experiments. The ${ }^{1} \mathrm{H}$ NMR spectra shows that PCDP were successfully synthesized from poly(CBA-DAH) and PEI 1.8kDa.

\section{Applications of PEI-conjugated bio-reducible polymers}

\section{Buffering capacity of PCDP}

Poly(ethylenimine) consists of many nitrogen atoms including primary, secondary, and tertiary amine groups. Those amine groups are able to enhance their buffering capacities. Those cause the subsequent endosomal or lysosomal rupture, and escape into the cytoplasm via a proton sponge effect ${ }^{31,32}$. PEI is able to provide some buffering capacity enhanced to the PCDP, leading to increase endosomal escape into the cytoplasm. The other studies had also shown the enhanced buffering capacity such as imidazole, histidine, and $\mathrm{PEI}^{33-37}$. In the range of pH 3-10, the buffering capacity of PCDP has measured by acid-base titration assay, and then the acid-base titration curve has evaluated in the endosomal $\mathrm{pH}$ range from 5.1 to 7.4. PCDP shows the increased buffering capacity more than that of poly(CBA-DAH). That is one of the evidences for PCDP, resulting more amino groups introduced to poly(CBA-DAH)-PEI. The results are supported that the buffering capacity enhanced may help the endosomal escape of the polyplexes.

\section{in vitro transfection experiment}

Both gWiz-Luc and gWiz-GFP genes had used to evaluate the gene transfection efficiency for PCDP, and then the polyplexes formed with PCDP. Including poly(CBA-DAH), Lipofectamine $\AA$ and PEI $25 \mathrm{kDa}$, the comparison groups has been also treated in various cancer cell lines ${ }^{1}$. The visualization of GFP expression for polymer/pDNA(gWizGFP) are directly displayed. The GFP gene expression of PCDP polyplexes increases with increasing formation ratios of polyplexes ranging from 1 to $10(\mathrm{w} / \mathrm{w}$ ratio). The comparison of groups including poly(CBA-DAH), Lipofectamine $\AA$ and PEI $25 \mathrm{kDa}$ shows a similar tendency to GFP gene expression in all cell lines. The visualized GFP gene expression and the mean fluorescence intensity (MFI) in the case of PCDP above $10 \mathrm{w} / \mathrm{w}$ ratios show higher than those of other groups ${ }^{1}$. That might be due to the buffering capacity increased by PEI on poly(CBA-DAH). Therefore, poly(CBADAH)-PEI[PCDP] shows the increased GFP gene expression efficiency. The efficiency of PCDP as a gene delivery system has obtained through the experiments of the cytotoxicity and cellular uptakes for PCDP/pDNA polyplexes. 


\section{Efficient Gene Delivery}

\section{Cytotoxicity of PCDP and PCDP/pDNA polyplexes}

The cytotoxicity of PCDP and PCDO/pDNA has performed to confirm in A549, Huh-7, and MiaPaCa-2 cells by the MTT assay. ${ }^{1}$ As the concentration of the treated PCDP and PCDP/ pDNA was increased from 1 to $20 \mu \mathrm{g} / \mathrm{mL}$, the viability of cell was slightly decreased. On the other hand, the maximum amount of PCDP used to form the polyplexes with pDNA was $10 \mu \mathrm{g} / \mathrm{mL}$ and the viability of cell was above $90 \%$ except in Huh-7 cells. The viability of cell for PEI $25 \mathrm{kDa}$ as a comparison group decreased significantly with increasing concentration up to $20 \mu \mathrm{g} / \mathrm{mL}$. There is no considerable cytotoxicity because PCDP consists of disulfide and amide bonds. Those degrade into non-toxic molecules in cells themselves ${ }^{38-41}$. The PCDP/ pDNA polyplexes have also observed for cytotoxicity. There is no considerable cytotoxicity at all for the formation ratios of polyplexes in the range of $1-20 \mathrm{w} / \mathrm{w}$ in all cell lines. On basis of the results for MTT assay, PCDP has no cytotoxicity. The results indicate that PCDP/pDNA might be safer than that of the other comparison groups as it uses to deliver pDNA.

\section{Cellular uptake of PCDP/pDNA polyplexes}

The cellular uptakes of PCDP/pDNA polyplexes were investigated for the various ratios of molecular weight in the range from 1 to 20 by FAC scan analyzer in the various lines of cancer cells. Poly(CBA-DAH), PEI 25kDa, and Lipofectamin ${ }^{\circledR}$ had also used as comparison groups with the formed polyplexes at optimized weight ratios of $1,2$ and 40 based on pDNA(1 $\mu \mathrm{g})$, respectively. The cellular uptake efficiency of PCDP polyplexes shows low at the ratio of molecular weight of 1 and 5. However, it shows almost similar efficiency at the ratios of molecular weights for 10 and more in the lines of cells. In order to compare with the controlled groups, the cellular uptake efficiency of PCDP polyplexes at a molecular weight ratio of 10 and 15 displayed. As shown in Figure 1, PCDP polyplexes display a similar cellar uptake and quantified cellular uptake (\%)

\section{B}
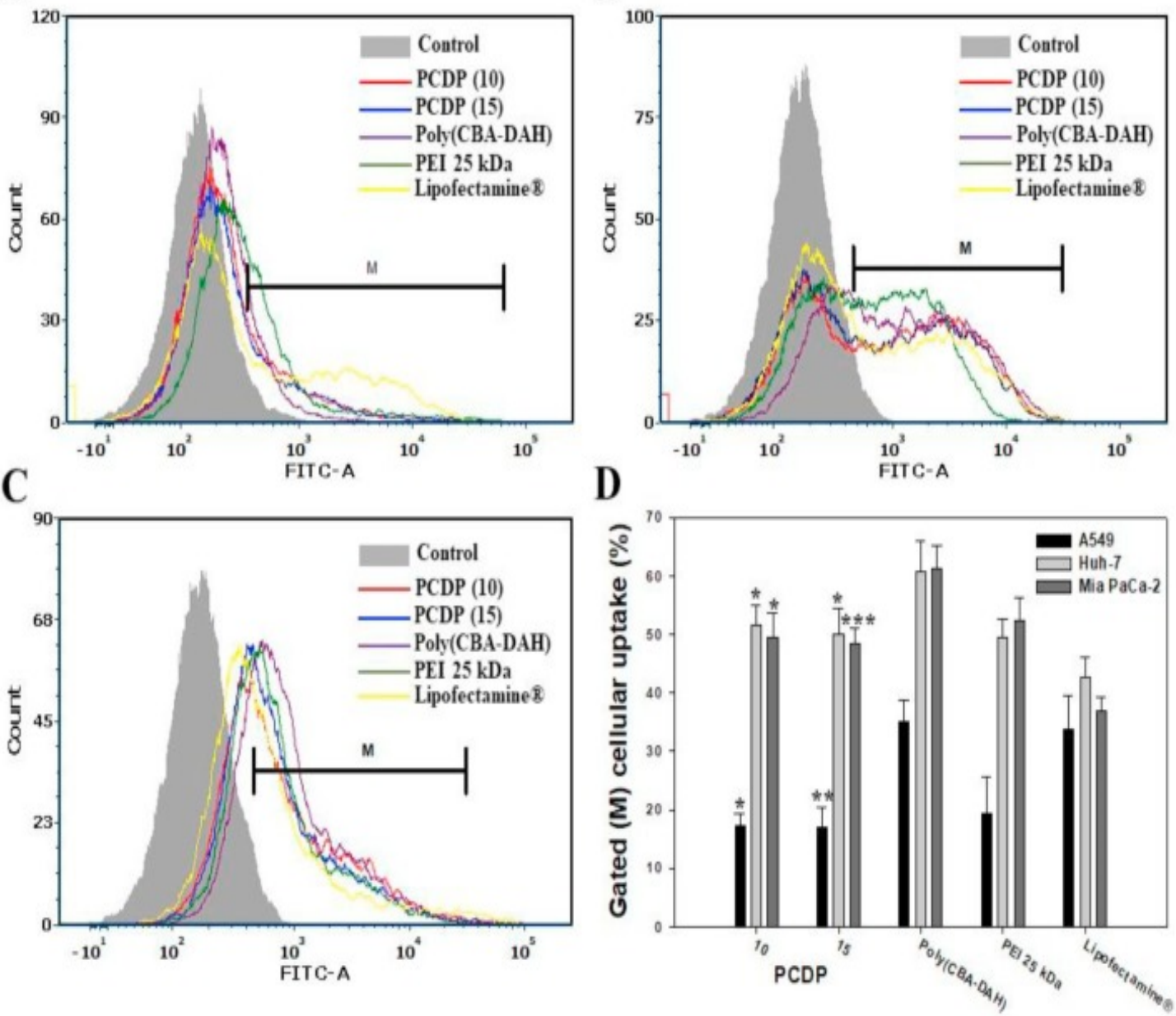

Figure 1: Cellular uptake of polyplexes in (A) A549, (B) Huh-7, and (C) Mia PaCa-2 cells. The YOYO-1 stained pDNA were formed the polyplexes with PCDP, poly(CBA-DAH), PEI $25 \mathrm{kDa}$, and Lipofectamine ${ }^{\circledR}$ at weight ratio based on pDNA (1 $\left.\mu \mathrm{g}\right)$, respectively. (D) The cellular uptake \% of quantification of cell internalization measured by FACs. Results are represented as mean \pm SD. $(\mathrm{n}=3) .{ }^{*} \mathrm{P}<0.05,{ }^{* *} \mathrm{P}<0.01,{ }^{* * *} \mathrm{P}<0.001$ versus $\mathrm{PEI} 25 \mathrm{kDa}$. 
with PEI 25kDa polyplexes in all cell lines. Those show better results than that of Lipofectamine ${ }^{\circledR}$ except that of A549 cells. All of the polymers tested are able to form polyplexes with a positive surface charge in nano-particle. The zeta potentials are in the range of 27-34 $\mathrm{mV}$ for PCDP in 102-128 $\mathrm{nm}$ particle sizes. The zeta potentials and particle sizes are $22 \mathrm{mV}$ and $120 \mathrm{~nm}$ for PEI $25 \mathrm{kDa}, 40 \mathrm{mV}$ and $<200 \mathrm{~nm}$ for poly(CBA-DAH) ${ }^{14,16}, 38 \mathrm{mV}$ and $150 \mathrm{~nm}$ for Lipofectamine ${ }^{42}$,repectively. Poly(CBA-DAH) polyplexes are showed a highest cellular uptake efficiency in all cell lines. The results are due to the highest positive charge density as well as surface hydrophobicity. The cellular uptake has affected by particle size, the hydrophobicity of surface, and the shape of materials ${ }^{43}$.

\section{VEGF silencing and cancer cell growth inhibition efficiency of PCDP/pshVEGF}

The VEGF siRNA expressing plasmid (pshVEGF) has constructed to inhibit VEGF expression of cancer cells and to express VEGF siRNA longer than directly delivering siRNA via methods mentioned above from previous works ${ }^{44}$.VEGF is a signal protein produced by cells that stimulates vasculogenesis and angiogenesis. The cancer cells can express VEGF, leading to the growth and metastasis of tumor via angiogenesis. Therefore, the disabling VEGF receptor function and inhibiting VEGF expression have used as a strategy to inhibit tumor growth and metastasis ${ }^{4-46}$. As shown in Figure 2, PEI-conjugated bio-reducible polymer
(PCDP) reacts with genetic materials such as pDNA(GFP) and pshRNA (VEGF) to give the results(upper; bottom). The upper photos shows the monitored pictures by fluorescent microscopy GFP expression of polyplexes against A549, Huh-7, and Mia PaCa-2 cells for 48hrs, respectively. The bottom figures show the weight ratios based on VEGF expression (\% of control) for control, PCDP, Poly(CBADAH), PEI 25kDa and Lipofectamine $\AA$, respectively.

The result indicates that the VEGF gene silencing by PCDP/pshVEGF polyplexes indirectly inhibits the cell proliferation and growth rates. The comparison groups, which used pshVEGF, show the decreased cell viability values than that of PCDP polyplexes.

\section{In vivo study}

As shown in Figure 3, the VEGF gene expressions in relation with gene silencing efficiency have measured by human VEGF ELISA. The cells were transfected by the polymers of pshVEGF. The VEGF expressions of PCDP polyplexes decreased dramatically at a weight ratio of 10 and 15. On the other hands, the others between the weight ratio of 10 and 15 are almost similar values. In addition, VEGF expressions (\% of control) for the PCDP are lower values of VEGF expression than those of PEI $25 \mathrm{kDa}$, Lipofectamine $囚$, and poly(CBA-DAH), respectively. These results are consistency in the efficiency of transfection assay using gWiz-GFP and gWiz-GFP. Comparing with

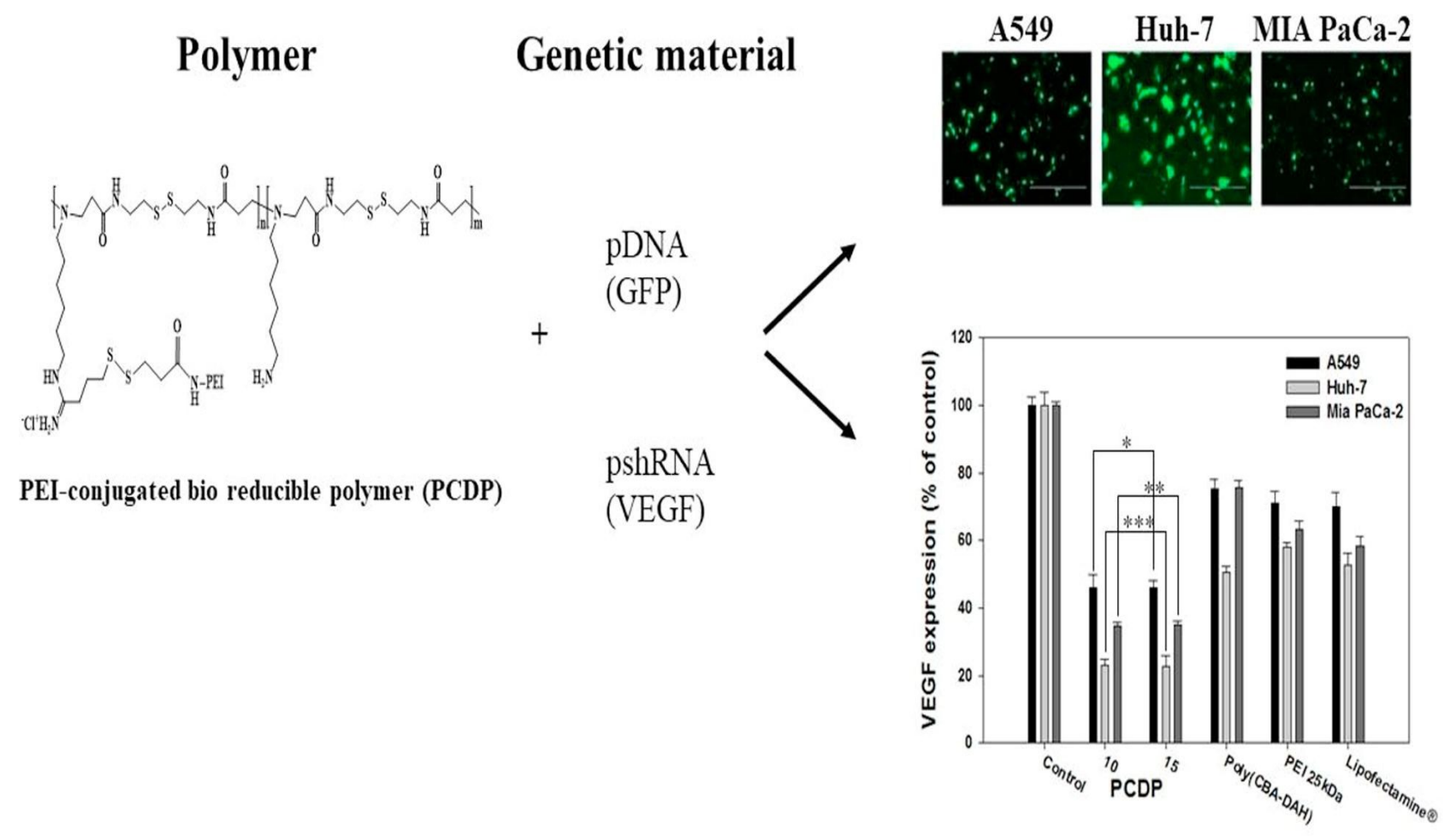

Figure 2: The results of PEI-conjugated bio-reducible polymer (PCDP) with genetic materials; (a) pDNA(GFP) and (b) pshRNA(VEGF) show A549, Huh 7, MIA PaCa-2, and diagrams in the right sides. 


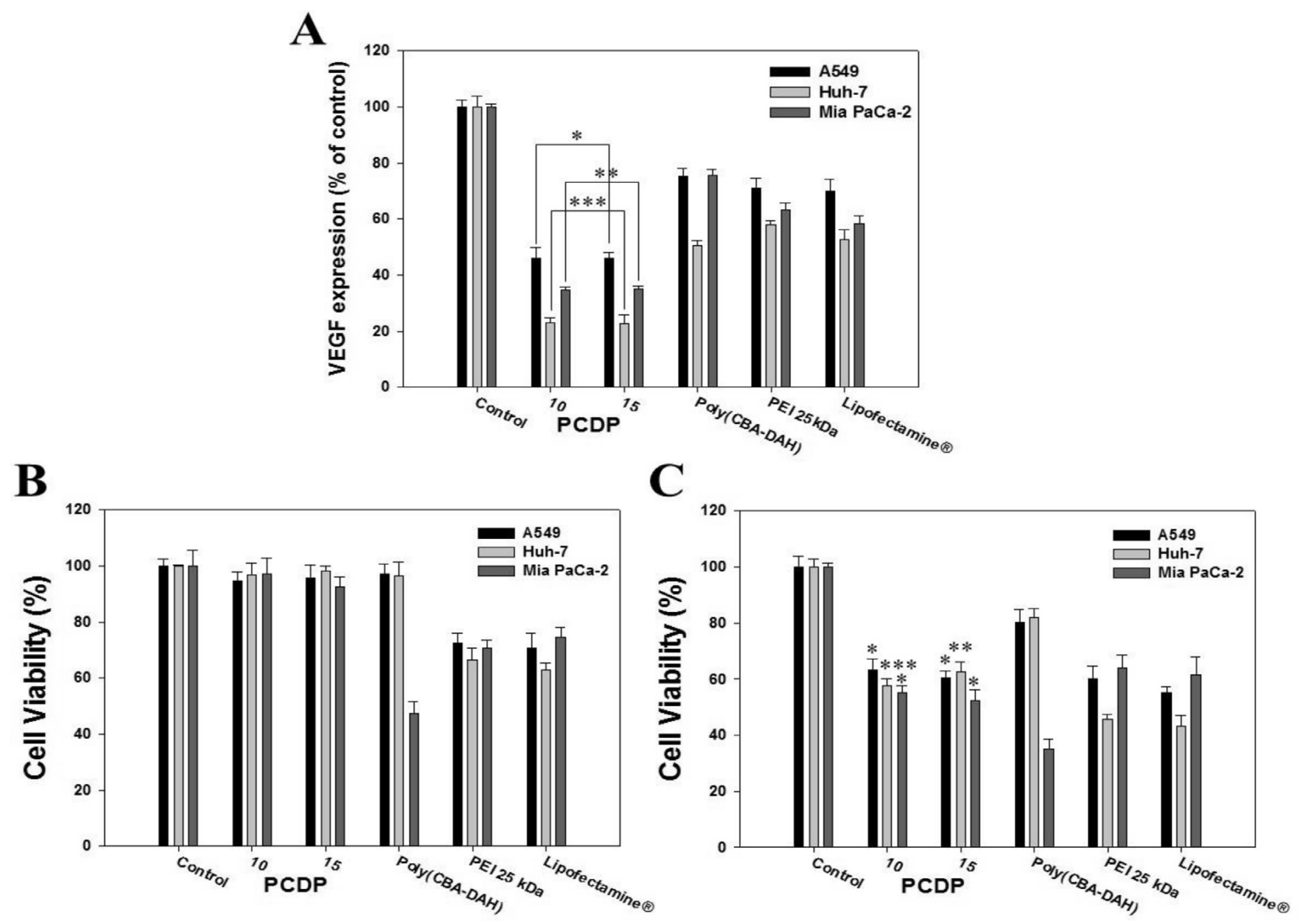

Figure 3: The down regulation of VEGF expression using pshVE delivery into the cancer cells for 48hrs by polyplexes. The VEGF epression measured by human VEGF ELISA kit. (A) Quantification of down regulated VEGF expression shown by relative VEGF expression percent (\%). Relative VEGF expression (\%) = Amount of VEGF (Treated)/Amount of VEGF (Control) x 100. (B) Cell growth inhibition of polymers with gWiz-Luc; (C) shVEGF polyplexes measured by MTT assay.

control cells non-treated, the gene silencing efficiency of PCDP polyplexes are shown on $54 \%, 77 \%$, and $66 \%(\mathrm{w} / \mathrm{w}: 10)$, and $55 \%, 78 \%$, and $65 \%(\mathrm{w} / \mathrm{w}$ : 15$)$ reduction of VEGF levels in A549, Huh-7, and MiaPaCa-2 cells, respectively.

The cell viabilities of PCDP polyplexes decrease from $95 \%$ (formed with gWiz-Luc) to $60 \%$ (formed with pshVEGF) as shown in Figure 3(B) and Figure 3(C). The results indicate that the VEGF gene silencing inhibits the cell proliferation indirectly. Comparing with the control groups used pshVEGF, they showed the cell viability decreased and lower than that of PCDP polyplexes. The reduced rates of cell viability associated with the results both gWiz and pshVEGF are $31 \%, 39 \%$, and $42 \%(P C D P, w / w: 10), 35 \%, 36 \%$, and $40 \%(\mathrm{PCDP}, \mathrm{w} / \mathrm{w}: 15), 17 \%, 14 \%$, and $12 \%$ [poly(CBADAH)], $12 \%, 21 \%$, and $6 \%$ (PEI 25kDa), and $15 \%, 20 \%$, and $13 \%$ (Lupofectamine ${ }^{\circledR}$ ) in A549, Huh-7, and MiaPaCa-2 cell, respectively. The PCDP polyplexes result in similar values with weight ratios (10 and 15) in all experiments and the optimal value of weight ratio is ten.

\section{Conclusion}

The design and synthesis of polymers for gene delivery systems have made over the past decade in our laboratory. Up to date, the PEI-conjugated bio-reducible polymers such as PCDP and poly(CBA-DAH) exhibit good candidate for the application of gene delivery. The VEGF gene silencing by PCDP/pshVEGF polyplexes indirectly inhibits the cell proliferation and growth rates. In the comparison with other groups used pshVEGF, they show the decreased cell viability values than that of PCDP polyplexes. PEI has many nitrogen atoms including primary, secondary and tertiary amine group that is able to increase binding affinity with pDNA, siRNA and mRNA. Those are stimulated to provide buffering capacity and positive charge to the polyplexes. The efficiency of PCDP for gene delivery is better than that of Lipofectamine ${ }^{\circledR}$ or poly(CBA-DAH). In the results of the VEGF expression, PCDP for A549, Huh-7, and MiaPaCa-2 cells is better than that of the other products tested. It has concluded that the PEI(1.8kDa)-PCDP synthesized in our laboratory is one of the good candidates as a pDNA, siRNA, and mRNA carrier for efficient gene delivery systems. 


\section{Acknowledgments}

This work was supported by the NIH Grant CA177932 and the Basic Science Research Program through the National Research Foundation (NRF) funded by the Ministry of Education, Republic of Korea.

\section{References}

1. Nam JP, Kim S, Kim SW. Design of PEI-conjugated bio-reducible polymer for efficient gene delivery. Int J Pharm. 2018; 545(1-2): 295305. doi: 10.1016/j.ijpharm.2018.04.051.

2. Stone D. Novel viral systems for gene delivery. Viruses. 2010; 2(4): 1002-1007.

3. Niidome T, Huang L. Gene therapy progress and prospects: nonviral vectors. Gene Ther. 2002; 9(24): 1647-1652.

4. Mahato RI, Smith LC, Rolland A. Pharmaceutical perspectives of nonviral gene therapy. Adv Genet. 1999; 41(2): 95-156.

5. Han SO, Mahato RI, Sung YK, et al. Development of biomaterials for gene therapy. Mol Ther. 2000; 25(5): 302-317.

6. Katz MG, Fargnoli AS, Williams RD, et al. Gene therapy delivery systems for enhancing viral and nonviral vectors for cardiac diseases: current concepts and future applications. Gene Ther. 2013; 24(11): 914-927.

7. Nayerossadat $\mathrm{N}$, Maedeh $\mathrm{T}$, Ali PA. Virial and nonvirial delivery systems for gene delivery. Adv Biomed Res. 2012; 1(1): 27-31.

8. Al-Dosari MS, Gao X. Non-viral gene delivery: principle, limitations and recent progress. AAPS J. 2009; 11(4): 671-681.

9. Layek B, Singh J. Amino acid grafted chitosan for high performance gene delivery: comparison of amino acid hydrophilicity on vector and polyplex characteristics. Biomacromolecules. 2013; 14(2): 485 494.

10. Bouard D, Alazard-Dany D, Cosset FL. Viral vectors: from virology to transgene expression. Br J Pharmacol. 2009; 157(2) 153-165.

11. Yin H, Kanasty RL, Eltoukhy AA, et al. Non-viral vectors for gene-based therapy. Nat Rev Genet. 2014; 15(8): 541-555.

12. Eroglu E, Tiwari PM, Waffo AB, et al. A non-viral pHEMA+chitosan nanosphere-mediated high-efficieny gene delivery system. Int J Nanomed. 2013; 8(10) 1403-1415.

13. $\mathrm{Xu} \mathrm{Q}$ Wang $\mathrm{CH}$, Pack DW. Polymeric carriers for gene delivery; chitosan and poly(amidoamine) dendrimers. Curr Pharm Des. 2010; 16(21): 2350-2368.

14. Kim TI, Ou M, Lee M, et al. Arginine-grafted bio-reducible poly(disulfide amine) for gene delivery systems. Biomaterials. 2009; $30(4)$ : 658-664.

15. Nam HY, Nam K, Lee M, et al Dendrimer type bio-reducible polymer for efficient gene delivery. J Control Release. 2012; 160(3): 592-600.

16. Ou M, Wang XL, Xu R, et al. Novel bio-degradable poly(disulfide amine) $\mathrm{s}$ for gene delivery with high efficiency and low cytotoxicity. Bioconjug Chem. 2008; 19(3): 626-633.

17. Doss CG, Debottam S, Debajyoti C. Glutathione-responsive nanotransporter-mediated siRNA delivery: silencing the mRNA expression of Ras. Protoplasma. 2013; 250(3): 787-792.

18. Hong R, Han G, Fernandez JM, et al. Glutathione-mediated delivery and release using monolayer protected nanoparticle carriers. J Amer Chem Soc. 2006; 128(4): 1078-1079.

19. Oupicky D, Li J. Bioreducible polycations in nucleic acid delivery: past, present, future trends. Macromol Biosci. 2014; 14(7): 908-922.

20. Wen HY, Dong HQ Xie WJ, et al. Rapidly disassembling nanomicelles with disulfide-linked PEG shells for glutathione-mediated intracellular drug delivery. Chem Commun (Camb). 2011; 47(12): 3550-3552.

21. Chakravarthi S, Jessop CE, Bulleid NJ. The role of glutathione in disulphide bond formation and endoplasmic-reticulum-generated oxidative stress. EMBO Rep. 2006; 7(3): 271-275.

22. Lee YS, Choi JW, Oh JE, et al. Human Relaxin Gene Expression Delivered by Bioreducible Dendrimer Polymer for Post-infarct Cardiac Remodeling in Rats. Biomaterials. 2016; 97: 64-175.

23. Nam EJP, Nam K, Nah JW, et al. Evaluation of Histidylated ArginineGrafted Bio-reducible Polymer to Enhance Transfection Efficiency for Use as a Gene Carrier. Mol Pharm. 2015; 12: 2352-2364.

24. Choi JW, Nam JP, Nam K, et al. Oncolytic Adenovirus Coated with Multidegradable Bio-reducible Core-Cross-Linked Polyethylenimine for Cancer Gene Therapy. Biomacromolecules. 2015; 16: 2132-2143.

25. Kim H, Nam K, Nam JP, et al. VEGF Therapeutic Gene Delivery Using Dendrimer Type Bio-reducible Polymer into Human Mesenchymal Stem Cells (hMSCs). J Control Rel. 2015; 220: 222-228.

26. Choi JW, Kim HA, Nam K, et al. Heptoma Targeting Peptide Conjugated Bio-reducible Polymer Complexed with Oncolytic Adenovirus for Cancer Gene Therapy. J Control Rel. 2015; 220: 691-703.

27. Nam K, Jung S, Nam JP, et al. Poly(ethylenimine) Conjugated Bioreducible Dendrimer for Efficient Gene Delivery. J Control Rel. 2015; 220: 447-455.

28. Fischer D, Bieber T, Li Y, et al. A novel non-viral vector for DNA delivery based on low molecular weight, branched polyethylenimine: effect of molecular weight on transfection efficiency and cytotoxicity. 1999; 16(8):v1273-1279.

29. Wang F, Gao L, Meng LY, et al. A neutralized non-charged polyethylenimine-based system for efficient delivery of siRNA into heart without toxicity. ACS Appl Mater Interfaces. 2016; 8(49): 33529-33538.

30. Nam JP, Park JK, Son DH, et al. Evaluation of polyethylene glycolconjugated novel polymeric anti-tumor drug for cancer therapy. Colloids Surf B Biointerfaces. 2014; 120: 168-175.

31. Benjaminsen RV, Mattebjerg MA, Henriksen JR, et al. The possible "proton sponge" effect of polyethylenimine(PEI) does not include change in lysosomal pH. Mol Ther. 2013; 21(1): 149-157.

32. Luu QP, Shin JY, Kim Yk, et al. High gene transfer by the osmotic polysorbitol-mediated transporter through the selective caveolae endocytic pathway. Mol Pharm. 2012; 9(80): 2206-2218.

33. Bello Roufai M, Midoux P. Histidylated polylysine as DNA vector: elevation of the imidazole protonation and reduced cellular uptake without change in the polyfection efficiency of serum stabilized negative polyplexes. Bioconjug Chem. 2001; 12(1): 92-99.

34. Pack DW, Putnam D, Langer R. Design of imidazole-containing endosomolytic biopolymers for gene delivery. Biotechnol Bioeng. $2000 ; 67(2): 217-223$.

35. Pires LR, Oliveira H, Barrias CC, et al. Imidazole-grafted chitosanmediated gene delivery: in vitro study on transfection, intracellular trafficking and degradation. Nanomedicine (Lond). 2011; 6(9): 14991512 .

36. YangY,XuZ,ChenS, etal.Histidylated cationicpolyorganophosphazene/ DNA self-assembled nanoparticles for gene delivery. Int J Pharm. 2008; 353(1-2) 277-282.

37. Zhang X, Duan Y, Wang D, et al. Preparation of arginine modified PEIconjugated chitosan copolymer for DNA delivery. Carbohydr Polym. 2015; 122: 53-59.

38. Liu C, Zhu Q Wu W, et al. Degradable copolymer based on amphiphilic N-octyl-N-quatenary chitosan and low-molecular weight polyethylenimine for gene delivery. Int J Nanomed. 2012; 7: 5339-5350. 
39. Petersen H, Merdan T, Kunath K, et al. Poly(ethylenimine derivative with an advantageous $\mathrm{pH}$-dependent hydrolytic degradation for gene delivery. Bioconjug Chem. 2002; 13(4): 812-821.

40. Yu H, Russ V, Wagner E. Influence of the molecular weight of bioreducible oligoethylenimine conjugate on the polyplex transfection properties. AAPS. 2009; 11(3): 445-455.

41. Zhao N, Roesler S, Kissel T. Synthesis of a new potential biodegradable disulfide containing poly(ethylene imine) copolymer crosslinked with click cluster for gene delivery. Int J Pharm. 2011; 411(1-2): 197-205.

42. Lee JH, Ahn HH, Kim KS Lee JY, et al. Polyethylenimine mediated gene delivery into rat pheochromocytoma PC-12 cells. J Tissue Eng Regen Med. 2008; 2(5): 288-295.
43. Frohlich E. The role of surface charge in cellular uptake and cytotoxicity of medical nanoparticles. Int J nanomed. 2012; 7: 55775591.

44. Kim HA, Nam K, Kim SW. Tumor targeting RGD conjugated bioreducible polymer for VEGD siRNA expressing plasmid delivery. Biomaterials. 2014; 35(26): 7543-7552.

45. Yang Y, Liu X, Zhang D, et al. Chitosan/VEGF-siRNA nanoparticle for gene silencing. J Control Release. 2011; 152(Suppl. 1): e160-e161.

46. Zibara N, Awada Z, Dib L, et al. Anti-angiogenesis therapy and gap junction inhibition reduce MDA-MB-231 breast/cancer cell invasion and metastasis in vitro and in vivo. Sci Rep. 2015; 5: 12598-9. 